\title{
Narrativas hipertextuais e visuais: ressignificações e novos cenários de formação na educação da era digital
}

\author{
Edemir Jose Pulita ${ }^{1}$, Gilberto Lacerda Santos ${ }^{2}$ \\ ${ }^{1}$ Programa de Pós Graduação em Educação - Universidade de Brasília (UnB) \\ Campus Universitário Darcy Ribeiro, Brasília - DF, 70910-900 \\ ${ }^{2}$ Faculdade de Educação - Universidade de Brasília (UnB) \\ edemirjose@hotmail.com, glacerdeunb.br
}

\begin{abstract}
This research assumes that the inclusion of technology in school has not reframed education by a disconnection from the experiences of their subjects. So we ask: what experiences are necessary in education before the cyberculture? We conducted an action research with future teachers theoretically discussing issues related to experience the look and images. Participants created six hypertextual and visual narratives that were analyzed and, from that, point to elements for reframe the experiences of the actors of formal education: (a) interaction of the subjects through TDICE;(b) new role of images in the current scenario; and (c) generation of immersive experiences in content.
\end{abstract}

Resumo. Essa investigação parte do pressuposto de que a inserção das tecnologias na escola não tem ressignificado a educação por uma desconexão com as experiências dos seus sujeitos. Assim, nos perguntamos: quais experiências são necessárias na educação diante da cibercultura? Realizamos uma pesquisa-ação com futuros professores discutindo questões relacionadas a experiencia do olhar e as imagens. Os participantes criaram seis narrativas hipertextuais e visuais que foram analisadas e, a partir disso, apontam-se elementos para ressignificar as experiências dos atores da educação formal: (a) interação dos sujeitos por meio das TDICE; (b) novo papel das imagens no cenário atual; e (c) geração de experiências de imersão nos conteúdos.

\section{Introdução}

A problemática geral que move essa pesquisa é balizada por três fatores: (a) a profusão das tecnologias digitais de informação, comunicação e expressão (TDICE) compreendidas em termos da diversidade de aparatos e dispositivos eletrônicos amplamente utilizados atualmente -, geraram transformações na sociedade, modificando modelos, sistemas e paradigmas em termos de velocidades, alcances, possibilidades e inovações; (b) os impactos possibilitados e produzidos por tais modificações nas identidades e subjetividades dos sujeitos, dos grupos e das relações sociais transformam os modos de se informar e de se comunicar, de se relacionar e de se expressar; (c) o choque provocado na lógica e na estrutura escolar, no modelo didático-pedagógico e no sistema educacional formal, a partir das novas perspectivas trazidas no bojo da profusão tecnológica e de suas transformações, questionam a escola e seus processos, 
demandando reconfigurações nas formas de ensinar e aprender. Apontamos como pressuposto dessa pesquisa o fato de que, na maioria dos casos, a inserção das TDICE nas instituições educativas formais não tem alcançado ressignificar a educação. Diante disso, nossa hipótese é a existência de uma desconexão das dinâmicas e experiências vividas pelos seus atores sociais dentro e fora dos muros escolares.

Diversos estudos apontam as dificuldades de inserção das TDICE nos processos da educação formal. Um estudo realizado por Figueiredo, Nobre e Passos (2015) apontou que, para além da infraestrutura e falta de profissionais de apoio, o principal desafio expresso por professores é explorar de maneira pedagógica os recursos tecnológicos. Por sua vez, Lima e Loureiro (2015) apontam uma falha na integração das TDIC na docência pela centralidade dada à figura do professor. Já Monteiro, Maia, Lima, Pires e Rego (2015) apontam em seu estudo uma deficiência tanto de disciplinas específicas sobre a inserção das TDIC na formação de futuros professores (Pedagogia), quanto falta de integração nas disciplinas gerais com essa temática. Dentre outros aportes necessários para se reverter esse quadro, a inclusão da palavra expressão no acrônimo TDICE sinaliza a importância dessa ação na utilização das tecnologias que, além de informativas e comunicativas, não devem desprezar as experiências expressivas por elas potencializadas aos seus sujeitos.

Uma primeira explicação para essas falhas na inserção é dada por Pretto (2010) ao apontar que as possibilidades trazidas pelas TDICE à educação não ultrapassam a simples utilização das ferramentas e recursos, ou seja, ocorrem sem o aproveitamento das características próprias da hipertextualidade e da cibercultura. "O que temos percebido é que, na maioria das vezes, as tecnologias digitais - e a internet, em particular - são tratadas como meras ferramentas auxiliares dos processos educacionais" [PRETTO, 2010, p. 307].Na mesma linha, Kenski (2013, p. 86) questiona: "o que é possível ensinar em um momento em que as informações estão tão pulverizadas, tão fragmentadas, tão acessíveis por diferenciados meios (e mídias) e, sobretudo, tão disponíveis?". A necessidade de mudanças é apontada pela autora quando afirma que "o que a escola e a ação dos professores necessitam é de revisão crítica e reorientação dos seus modos de ação" (2013, p. 86) e, para tanto, serão necessárias reconfigurações para que surjam "novos papéis para professores e alunos" (2013, p. 95).

Entre diversos aspectos que podem ser focalizados nas interfaces entre educação e tecnologias, o presente artigo problematiza os limiares entre imagens, TDICE e educação, conforme Nova (2003, p. 191) ao afirmar que "faz-se urgente o reconhecimento das imagens enquanto imagens estruturantes de um novo mundo. É necessário saber 'ler' essas novas imagens, para que elas não nos apareçam enquanto Franksteins. Esse é um dos papéis da educação desse novo milênio".

Partindo do questionamento feito por Walter Benjamin (2013, p. 86): "Na verdade, de que nos serve toda a cultura se não houver uma experiência que nos ligue a ela?", a pergunta geral que moveu a presente pesquisa foi: como transformar qualitativamente a inserção e uso das TDICE, ou seja, que experiências devem ser construídas na educação formal em consonância com a atual cibercultura? Para construir respostas à questão realizamos uma pesquisa-ação [THIOLLENT, 2011] na qual abordamos um grupo de 11 futuros professores na disciplina Tópicos Especiais em Tecnologias Educacionais ofertada pela Faculdade de Educação da Universidade de 
Brasília com o objetivo de apontar elementos significativos para a reflexão das reconfigurações da educação formal e dos novos cenários possíveis para a formação na era digital.

$\mathrm{Na}$ sequência apresentaremos o quadro teórico contextualizado que baseou tanto a pesquisa quanto as leituras e discussões com os estudantes. Em seguida relataremos os parâmetros da investigação e a análise de dados. Ao final apresentaremos os resultados obtidos e as conclusões que construímos diante da investigação.

\section{A experiência do olhar e as linguagens imagética e fotográfica}

A cibercultura é caracterizada por Rüdiger $(2013$, p. 7) como "uma formação histórica de cunho prático e cotidiano, cujas linhas de força e rápida expansão, baseadas nas redes telemáticas, estão criando, em pouco tempo, um campo de interrogação intelectual pujante, dividido em várias tendências de interpretação". Diante disso, o autor (2013, p. 8) afirma que "a revolução cibernética exige uma reestruturação dos programas e processos educacionais".

Sobre a estrutura hipertextual das TDICE, Lévy (1990, p. 29-31) afirma que esta possui seis princípios abstratos que regem a sua arquitetura e linguagem, baseado na ideia de hipertexto: metamorfose, heterogeneidade, multiplicidade, exterioridade, topologia e mobilidade de centros. Tais características apontam para uma nova relação com o saber: "o saber-fluxo, o trabalho-transação de conhecimentos, as novas tecnologias da inteligência individual e coletiva mudam profundamente os dados do problema da educação e da formação" [LÉVY, 2007, p. 158], diante da qual se deve construir "novos modelos do espaço do conhecimento" e "um novo estilo de pedagogia".

Ao problematizar as interfaces entre TDICE e a educação atual, Sibilia (2012, p. 190) escreve que "trata-se de uma tentativa de produzir a hibridação de dois regimes tão diferentes - inclusive contraditórios, ou até incompatíveis - como são o dispositivo pedagógico disciplinar e a conexão em redes informáticas”. No fluxo midiático digital ocorre uma banalização e uma saturação tanto das imagens quanto das palavras que, segundo Sibilia (2012, p. 86), em vez de garantir "experiências com seu peso capaz de marcar corpos e subjetividades, elas patinam ou deslizam sem se prender a nada, (...) em vez de lhe dar espessura fazendo-a se deter ou interrompendo seu devir". Concluindo, a autora [2012, p. 86] escreve que "em seu excesso sem densidade, tanto as imagens como as palavras se mostram impotentes para desacelerar esse fluxo ou para lhe dar coesão: não conseguem se condensar em diálogo nem em pensamento".

Essa problematização das imagens e das experiências atuais com as TDICE nos levou a buscar um aprofundamento sobre a experiência do olhar. Encontramos em Rouanet (1988) duas frases provocadoras de inúmeras reflexões. A primeira, quando Rouanet (1988, p. 127) reflete acerca da Encyclopedie e afirma que "não se vê sempre o que se olha, mas se olha sempre o que se vê". Na segunda, o autor (1988, p. 127) escreve que "sem o olhar a visão é ilusória, sem a visão o olhar é inútil. [...] a Ilustração é as duas coisas: olhar a serviço da visão, visão funcionalizada pelo olhar". Essas provocações, quando lançadas nas possibilidades de questionamento ao olhar dos sujeitos da cibercultura, nos remetem a mesma necessidade encontrada por Rouanet (1988, p. 128): a da construção de uma “pedagogia do olhar". Outra discussão 
interessante acerca da diferença entre o ver e o olhar é realizada por Cardoso (1988). Este autor (1988, p. 348) afirma que o ver tem uma conotação de discrição, passividade e reserva. "Nele, um olho dócil, quase desatento, parece deslizar sobre as coisas; e as espelha e registra, reflete e grava" (1988, p. 348). Já o olhar possui outra natureza, pois "se enreda nos interstícios de extensões descontínuas, desconcertadas pelo estranhamento", em busca de "limites, lacunas, divisões e alteridade, conforma-se a um espaço aberto, fragmentado e lacerado" (1988, 349). "Ela, a simples visão, supõe e expõe um campo de significações, ele, o olhar - necessitado, inquieto e inquiridor - as deseja e procura, seguindo a trilha do sentido. O olhar pensa; é a visão feita interrogação" (1988, p. 349).

Apesar de referirem-se as inovações técnicas e tecnológicas de sua época, quais sejam, da fotografia e do cinema, Walter Benjamin (1985) elabora reflexões profundas acerca das técnicas, da sua recepção e das possibilidades de experiência com as mesmas. As questões da experiência são tratadas em termos de uma experiência verdadeira (Erfahrung), de vivência (Erlebnis) e do choque (Chockerlebnis). A primeira é uma experiência coletiva com um sujeito localizado historicamente e consciente. A segunda é apenas as vivências cotidianas, normalmente relacionadas a automatismos e condicionamentos. E o choque é tratado como uma antiexperiência ou a impossibilidade de uma experiência ocorrer. Nesses termos, uma primeira figura apresentada por Benjamin (1985, p. 205) é a do narrador, quando afirma, por exemplo, que este imprime em suas narrativas suas marcas, como o oleiro deixa suas digitais no barro do vaso que constrói. Outra figura que se destaca nos escritos benjaminianos e que relacionamos à experiência do olhar é a do flâneur, que nos interessa pela experiência do olhar que realiza. Benjamin afirma que "seu olho aberto e seu ouvido atento procuram coisa diferente daquilo que a multidão vem ver", e conclui escrevendo que "os homens de gênio, em sua maioria, foram grandes flâneurs, mas flâneurs laboriosos e fecundos" [LAROUSSE apud BENJAMIN, 2009, p. 497].

Nossa intenção ao problematizar as questões da percepção, do olhar e da experiência é transpor tais reflexões aos sujeitos das mídias comunicacionais da era digital e perguntar: Quais as condições de receptibilidade desses sujeitos? Que tipos de olhares são oferecidos e possibilitados a eles? Quais as possibilidades de realização de experiências verdadeiras, no sentido benjaminiano? Tais reflexões apontarão se o sujeito das atuais mídias comunicacionais será apenas um consumidor e usuário ou um sujeito ativo e protagonista das mudanças possibilitadas pela profusão midiática atual. Entre outras possibilidades, entrevemos nas linguagens imagética e fotográfica, maximizadas atualmente pelas TDICE, importantes aportes para a compreensão das mudanças em curso e da análise de seus impactos na educação formal.

No livro intitulado Política e poética das imagens: implicações para o campo da educação, os organizadores Ferrari e Castro (2012, p. 12) afirmam que é necessária uma "articulação entre imagens, educação e processos de subjetividades". Os pesquisadores [2012, p. 13] partem do conceito de imagens "como resultados de processos históricos e culturais, com implicações na construção dos sujeitos e dos objetos" e afirmam que elas constroem uma determinada realidade. "Diante disso, podemos pensar sobre o papel das imagens e dos discursos na educação do olhar, nos convidando a questionar sobre as práticas culturais que educam o nosso olhar e sobre os efeitos desse olhar sobre quem olha" (2012, p. 14). Aprofundando essas questões Flusser (2011) escreve: 
V Congresso Brasileiro de Informática na Educação (CBIE 2016)

Anais do XXII Workshop de Informática na Escola (WIE 2016)

Imagens são mediações entre homem e mundo. O homem 'existe', isto é, o mundo não lhe é acessível imediatamente. Imagens têm o propósito de lhe representar o mundo. Mas, ao fazê-lo, entrepõem-se entre o mundo e homem. Seu propósito é serem mapas do mundo, mas passam a ser biombos. O homem, ao invés de se servir das imagens em função do mundo, passa a viver em função das imagens. Não mais decifra as cenas da imagem como significados do mundo, mas o próprio mundo vai sendo vivenciado como conjunto de cenas. [p. 17].

A respeito de nossa relação com as imagens, José Saramago, em entrevista registrada no documentário Janela da Alma (2001) afirma: "Nós nunca vivemos tanto na Caverna de Platão como hoje. Hoje é que estamos vivendo de fato na Caverna de Platão. Porque as próprias imagens que nos mostram da realidade, de certa maneira substituem a realidade". Por um lado, nos parecem extremamente preocupantes tais questões apresentadas em termos de como a educação será impactada e reagirá frente ao atual regime de visibilidade imagético e pela cultura visual cada vez mais solidificada. Por outro lado, tais novas possibilidades, representadas pelas linguagens imagética e fotográfica, com suas potencialidades em termos de equipamentos e rapidez de divulgação, nos apontam para mudanças e transformações necessárias na educação formal.

O que nos preocupa é evitar uma anestesia ou uma cegueira frente a um imagético que pode não ultrapassar o choque. Essa busca da experiência com as linguagens imagética e fotográfica foi realizada na presente pesquisa e busca refletir o que aconselha Bondía (2002, p. 24):

A experiência, a possibilidade de que algo nos aconteça ou nos toque, requer um gesto de interrupção, um gesto que é quase impossível nos tempos que correm: requer parar para pensar, parar para olhar, parar para escutar, pensar mais devagar, olhar mais devagar, e escutar mais devagar; parar para sentir, sentir mais devagar, demorar-se nos detalhes, suspender a opinião, suspender o juízo, suspender a vontade, suspender o automatismo da ação, cultivar a atenção e a delicadeza, abrir os olhos e os ouvidos, falar sobre o que nos acontece, aprender a lentidão, escutar aos outros, cultivar a arte do encontro, calar muito, ter paciência e dar-se tempo e espaço.

\section{Métodos}

A pesquisa qualitativa de abordagem sócio-histórica foi empregada, conforme Freitas (2007, p. 26) expressa ao afirmar que a pesquisa e a construção de conhecimentos se dão em um processo interativo entre sujeitos que constroem, conjuntamente, uma "experiência dialógica". A organização da disciplina Tópicos Especiais em Tecnologias Educacionais foi planejada em consonância com a pesquisa realizada, sendo os participantes informados e conscientizados disso. As questões avaliativas, as reflexões propostas e a atividade final foram aspectos avaliados em conjunto com os 11 participantes da investigação ( 7 do curso de Pedagogia e os demais estudantes de licenciaturas). $\mathrm{O}$ método utilizado foi o de pesquisa-ação, como considerado por Thiollent (2011, p. 7) ao afirmar que pesquisadores e pesquisados se reúnem para resolução de problemas levantados conjuntamente e em busca de um "avanço a ser dado para que sejam formuladas adequadas respostas sociais, educacionais, técnicas e/ou políticas". 
As leituras e discussões teóricas da disciplina corresponderam às tratadas na fundamentação teórica desse artigo. Dessa forma, foram indicadas para leitura textos de Paula Sibilia (2012): O desmoronamento do sonho letrado: inquietação, evasão e zapping e Salas de aula informatizadas e conectadas: muros para quê?, e de Walter Benjamin (1985): O narrador e A obra de arte na era de sua reprodutibilidade técnica. O filme Janelas da Alma, de João Jardim e Valter Carvalho (2001), também foi visto e discutido pelas provocações trazidas a respeito do olhar e das formas de utilização do imagético. $O$ trabalho final da disciplina consistiu na elaboração de uma Narrativa hipertextual e visual, cuja temática foi a experiência do olhar e as linguagens imagética e fotográfica. O foco escolhido e decidido coletivamente foi Brasília. A narrativa deveria ser composta por fotografias feitas pelos participantes e a forma de montagem ficaria a cargo de cada indivíduo ou grupo. O diário de bordo deveria conter uma descrição do processo de realização e do produto. Foram elaboradas 6 narrativas: 3 individuais, 2 em dupla e 1 em um grupo de 4 integrantes.

A seguir apresentaremos os resultados baseados nos diários de bordo através da análise de seus conteúdos. Tal procedimento será baseado na Análise de conteúdo proposta por Bauer (2015, p. 191), uma vez que os textos (dados) produzidos e agora lidos e interpretados, o serão "em termos de sua fundamentação nos materiais pesquisados e sua congruência com a teoria do pesquisador, e à luz de seu objetivo de pesquisa". Dessa forma, partindo-se das citações de trechos textuais escritos pelos participantes serão formuladas categorias baseadas no percurso teórico e reflexivo realizado com a finalidade de construção de respostas à questão norteadora da pesquisa.

\section{Resultados e Discussão}

Todas as narrativas foram montadas em sequência utilizando o programa movie maker. Em todas as narrativas existem fundos musicais, os quais além de se adaptarem as temáticas específicas de cada narrativa buscam impactar de alguma maneira os expectadores com suas letras e ritmos. Duas narrativas ( 1 e 6) se basearam na Copa do Mundo, uma nos esportes em locais públicos (Narrativa 2), uma no Movimento Surdofoto (Narrativa 3), uma na Universidade de Brasília (Narrativa 4) e uma no bairro em que a participante mora (Narrativa 5). Nos limites desse artigo nos deteremos na análise do que foi expresso nos diários de bordo.

A primeira categoria que constatamos refere-se aos Indicadores da experiência do olhar, a qual foi expressa em todos os diários de bordo. Ao produzirem as fotos, todos os participantes relatam que buscaram qualificar e diversificar o olhar. Por exemplo, tanto a Participante 1 quanto o quarteto que realizou a Narrativa 6, ambos sobre a Copa do Mundo, buscaram mostrar contrastes: de um lado a festa e a publicidade e, de outro, as manifestações contra sua realização por denúncias de irregularidades. A experiência de um olhar diversificado é manifestada pela Participante 1 quando afirma: "Conhecer Brasília não é só olhar para os lados e se maravilhar com a Catedral, o Memorial JK, a torre de Tv ou o Congresso, mas sim olhar para cima e perceber e avaliar o nosso céu".

A decisão de trabalhar juntas da Dupla da Narrativa 2 foi baseadas na experiência de olhar de ambas: "levamos estilos de vida parecidos e amamos Brasília, seria um olhar parecido e ao mesmo tempo diferente o que sempre enriquece um 
trabalho nesse sentido". Já a busca de expressão da experiência do olhar foi expressa pela Participante 3, ao integrar fotos de dois recursos: "Para meu trabalho final, a ideia é usar fotos do 'Movimento Surdofoto', como a tentativa de mostrar o olhar do surdo. Em contrapartida, relacionar com o olhar de um casal de turistas, hospedados em minha casa". As questões da experiência do olhar fez com que a Participante 4 tivesse longas reflexões, mobilizasse amigos e parentes e caminhasse pelo lugar onde vive: "vi lugares que já passei muito por eles e que hoje estão diferentes, muitos passam despercebidos no dia-a-dia".

As questões da experiência do olhar também levaram diversas participantes a se perguntarem sobre o olhar de quem assistiria as narrativas, levantando as questões relacionadas também à montagem da mesma. A Participante 3 declara: "se eu colocar o poema na minha 'narrativa' será que vai direcionar o olhar das pessoas a um mesmo foco?". Fazendo referência a opção de não realizar nenhum tratamento das imagens fotografadas, as participantes da Dupla que fez a Narrativa 5 afirmam: "A proposta é de que as imagens expostas devam ser 'tratadas' pelo olhar - emoções, experiências etc. de cada um presente em sala de aula".

A segunda categoria que vislumbramos nos diários de bordo refere-se aos Elementos relacionados às linguagens imagética e fotográfica e é expressa pela Participante 1 nos seguintes termos: "Durante todo o tempo (...) estive planejando aonde, como e porque tirar uma ou várias fotos". Vários participantes relataram a "caça" e a "saga" que se dispuseram para conseguirem as fotos: "Peguei minha câmera fotográfica e então fui atrás do que queria" [Participante 1] e "começamos nossa saga em busca de fotos incríveis em lugares lindos" [Dupla da Narrativa 2]. Essa dupla expressa a preocupação que todos tiveram em planejar e desenvolver o trabalho: "depois de muitos debates sobre possíveis formas, decidimos que tiraríamos todas as fotos no mesmo dia e que a sequência das fotos seria colocada pelo decorrer do dia, pela claridade, pela mudança do sol". Também pelas fotografias apresentadas na Narrativa 6 percebe-se a preocupação em diversificar o foco das fotos, pois ao apresentarem a Copa do Mundo (estádio e inclusive jogos que algumas integrantes assistiram), incluíram na Narrativa fotos das manifestações, do aeroporto, dos pontos turísticos da cidade, bem como de pontos com dificuldades e da periferia. A participante que elaborou a narrativa 3 descreve a dificuldade em selecionar e ordenar as fotografias e a necessidade de encontrar uma música que colaborasse com a construção da mensagem desejada. A mesma preocupação é expressa pela dupla da Narrativa 2 ao afirmarem que "nenhuma de nós é fotografa profissional e nem nosso intuito era tirar fotos que parecessem e sim clicar momentos que transmitissem essa diversidade que vivemos por frequentar esses lugares".

A Participante 4 mostra em sua Narrativa bancos de praças e pontos de ônibus presentes em seu bairro, pintados com temas referentes a locais turísticos de Brasília. Ao fazer as fotografias e montar o vídeo, a Estudante começou fotografando apenas as imagens e depois, ampliando o zoom, mostrando que estão presentes em seu bairro, valorizando, como por ela expresso, "a Brasília dentro de Brasília". Essas questões fizeram a participante perceber uma interdisciplinaridade na reflexão:

$\mathrm{Na}$ rua pensei em retratar a arte do lugar onde moro, pensei em retratar o contraste entre bens públicos na mesma região, ou mostrar o lugar que moro ao meu olhar. Mas com as fotos já no computador, em casa, pude fazer uma 
V Congresso Brasileiro de Informática na Educação (CBIE 2016)

Anais do XXII Workshop de Informática na Escola (WIE 2016)

reflexão e lembrar de tudo o que foi discutido ao longo do semestre na disciplina e também de outras disciplinas da Faculdade de Educação como História, Identidade e Cidadania, Educação em Geografia e Fundamentos da Arte na Educação, por exemplo [Participante 4].

Com a temática "O despercebido da UnB", a dupla da Narrativa 5 descreve assim sua busca pelas imagens:

Diante da correria dos dias, tudo isso passava despercebido aos meus olhos e ao vidro do carro. Então, com a proposta na cabeça e o celular nas mãos saímos a caminhar pelo campus Darci Ribeiro e 'descobrimos' muita coisa, muitas pessoas e muitas manifestações artísticas.

Consideramos a terceira categoria como as Reflexões acerca dos impactos dessa experiência para a educação formal. Nesse aspecto, a Participante 1 conceitua muito bem a intenção geral com a proposta da produção das narrativas ao afirmar que "fazer uma narrativa visual é verificar que olhar aquele que fotografa lança sobre o que capta no momento do seu clique e buscar compreender o que pretende expressar pelos elementos que revela sua imagem". Vemos a reverberação dessa afirmação nessa afirmação da dupla da Narrativa 2: "A reconstrução do olhar do aluno para a escola e a ressignificação do seu papel que vão fazer o processo educativo ganhar um sentido concreto novamente". Na sequência, em seu diário de bordo, essa dupla afirma: "o estímulo pelo olhar mais profundo e crítico pelos assuntos mais simples até os mais complexos e o meio que será utilizado para instigar esse processo, que vai ser o grande diferencial na construção educacional".

O interesse que foi despertado em uma integrante da Dupla da Narrativa 2 ao afirmar que "quanto as orientações do professor foram que colocássemos as nossas impressões, nosso olhar da nossa linda cidade, foi num estalo que pensei em ligar aos esportes, que fazem parte do meu dia-a-dia e que tornam a minha cidade insubstituível", refletiu em um segundo momento, no qual o dialogismo e a pluralidade de olhares foram expressos, quando a integrante afirma: "Brasília da arquitetura, dos políticos corruptos, dos ipês maravilhosos e da diversidade do esporte!" Preocupações semelhantes são expressas pela aluna que compôs a Narrativa 3 quando afirma:

Terminado (sic) essa construção, percebo que o que quero realmente expor, mostrar, ensinar a ver, não depende somente de minha produção, mas de como meu leitor, carregado de suas próprias informações, sentimentos, leituras de mundo, contexto e outras infinitas possibilidades de intromissão, poderão dar qualquer interpretação desse recorte visual. Porém, não seria mesmo essa a função da escola?

Nesse sentido, uma integrante da dupla que criou a Narrativa 2 afirma: "Acredito que o desafio dessa nova geração de professores e também dos antigos, que podem sempre se reciclar, é descobrir maneiras novas de estimular os alunos a se interessarem pelo que é proposto dentro da escola". Concluímos essa categoria com a fala da aluna que compôs a Narrativa 5, pois expressa de forma sintetizadora a opinião da vários participantes:

É necessário que eduquemos nossos alunos para se libertar, se libertar de não apenas enxergar, através dos olhos dos outros ou dos seus próprios olhos, que estão sendo cegados pela excesso de imagens ao qual estão sujeitos todos os dias, mas os próprios professores não olham para seus alunos e não percebem o seu modo de olhar ou ver o mundo. É preciso valorizar as experiências de 
cada olhar, cada criança tem um olhar diferente, mas as escolas estão condicionando os alunos a olharem o mundo de uma mesma forma, em um ambiente inibidor, não incentivando as crianças a desenvolverem a sua capacidade de criatividade e imaginação.

\section{Conclusões}

A pesquisa relatada mostra uma experiência embrionária, mas que aponta elementos que poderão ser retomados e desenvolvidos em diversas dimensões. Vemos que esse é um desafio de todos os estudos nas interfaces entre educação, tecnologias e comunicação, visto, por um lado, a hipertextualidade dos seus aspectos e, por outro, a complexidade dos cenários em um país de dimensões continentais e realidades tão distintas.

Especificamente em relação às questões aqui discutidas da experiência, do olhar e das imagens diante das TDICE, vemos que elas apontam para ressignificações que visam diminuir a desconexão das dinâmicas e experiência vividas pelos atores sociais dentro e fora da escola, as quais, segundo nossas análises conclusivas, explicitam-se em, ao menos, três aspectos: (a) ressignificações acerca da interação dos sujeitos (tanto professores quanto estudantes) da educação formal por meio das TDICE: as mídias comunicacionais devem valorizar, situar e/ou criar experiências aos sujeitos, diminuindo os muros e lançando pontes entre o intra e extra muros escolares; (b) ressignificações do papel das imagens no cotidiano dos sujeitos e no contexto de construção de conhecimento: A produção e leitura de imagens proporcionada pelas TDICE possibilitam novas abordagens na educação formal, principalmente sob o enfoque da experiência do olhar; e (c) ressignificações da experiência de imersão dos discentes nos conteúdos que lhes são propostos pela educação formal: diagnóstico dos conhecimentos prévios bem como das histórias de vida dos estudantes, reconhecimento de interesses e relações já estabelecidas configuram uma abordagem que afeta o interesse e o envolvimento dos sujeitos no processo.

A experiência das Narrativas hipertextuais e visuais apontam elementos significativos para a reflexão das reconfigurações da educação formal com a inserção das TDICE e, também, indicativos dos novos cenários possíveis para a formação escolar, colegial, acadêmica e docente na era digital. Para isso confluem, ao menos, dois aspectos: (a) nas interfaces entre educação e TDICE, se foi um avanço ir dos produtos aos processos, será um salto enorme pensar tanto novos processos de produção quanto a produção de novos processos; e (b) para a construção de uma pedagogia da autonomia na era digital é imprescindível respeitar-se o que é apontado por Paulo Freire como sendo o "primeiro saber (...) necessário à formação docente: Saber que ensinar não é transferir conhecimento, mas criar as possibilidades para a sua própria produção ou a sua construção" [Freire, 2013, p. 47].

\section{Referências}

Bauer, M. W. (2015) “Análise de conteúdo clássica: uma revisão”. In: Bauer, M. W.; and Gaskell, G. (Org.). Trad. de Pedrinho A. Guareschi. Pesquisa qualitativa com texto, imagem e som: um manual prático. 13. ed. Petrópolis, RJ: Vozes.

Benjamin, W. (1985) Obras Escolhidas: Volume 1 - Magia e técnica, arte e política. Trad. de Sergio Paulo Rouanet. São Paulo: Brasiliense. 
V Congresso Brasileiro de Informática na Educação (CBIE 2016)

Anais do XXII Workshop de Informática na Escola (WIE 2016)

. Passagens. (2009) Trad. Irene Aron. BH: Editora UFMG. . (2013) O anjo da história. Trad. João Barrento. BH: Autêntica.

Bondía, J. L. (2002) "Notas sobre a experiência e o saber de experiência". Trad. de João Vanderley Geraldi. Ver. Bras. de Educação. n 19, p.20-28, jan./abr.

Cardoso, S. (1988) "O olhar dos viajantes". In: Novaes, Adauto et al. O olhar. São Paulo: Companhia das Letras, p. 347-360.

Ferrari, A. and Castro, R. P. (2012) Política e poética das imagens como processos educativos. Juiz de Fora: Ed. UFJF.

Figueiredo, G. L. R., Nobre, I. A. M. and Passos, M. L. S. (2015) "Tecnologias Computacionais na Educação: Desafios na Prática Docente". In Anais do XXI Workshop de Informática na Escola. Maceió, AL, 2015.

Freire, P. (2013) Pedagogia da autonomia. Rio de Janeiro: Paz e Terra.

Freitas, M. T. (2007) “A perspectiva sócio-histórica: uma visão humana da construção do conhecimento". In: Freitas, M. T.; Jobim e Souza S.; Kramer, S. (Org.). Ciências humanas e pesquisa: leituras de Mikhail Bakhtin. 2. ed. São Paulo: Cortez, p. 26-38.

Flusser, V. (2011) Filosofia da caixa preta. São Paulo: Annablume.

Janela da alma. (2001) Direção: Jaime Jardim e Walter Carvalho. Estúdio Europa Filmes. (73 minutos).

Kenski, V. M. (2013) Tecnologias e tempo docente. Campinas, SP: Papirus.

Lévy, P. (1990) Les Technologies de l'intelligence. Paris: La découverte.

. Cibercultura. (2007) Tradução Carlos Irineu da Costa. São Paulo: Editora 34.

Lima, L. and Loureiro R. C. (2015) “A integração entre Docência e Tecnologias Digitais da Informação e Comunicação na Formação de Licenciandos". In Anais do XXI Workshop de Informática na Escola. Maceió, AL, 2015.

Monteiro, J. A. A., Maia, D. L., Lima, D. C., Pires, G. R. and Rego, L. K. F. (2015) "Formação Inicial Docente para as TDIC: Análise a Partir do Curso de Pedagogia do Campus Central da UFRN". In Anais do XXI Workshop de Informática na Escola. Maceió, AL, 2015.

Nova, C. (2003) "Imagem e educação: rastreando possibilidades". In: Alves, L.; Nova, C. (Org.). Educação e Tecnologia. Salvador: Editora da UNEB, p. 180-196.

Pretto, N. (2010) "O desafio de educar na era digital: educações”. Rev. Port. de Educação, Braga , v. 24, n. 1, p. 95-118.

Rouanet, S. P. (1988) O olhar iluminista. In: NOVAES, Adauto et al. O olhar. São Paulo: Companhia das Letras, p. 125-148.

Rüdiger, F. (2013) As teorias da cibercultura. Porto Alegre: Sulina.

Sibilia, P. (2012) Redes ou paredes. Trad. de Vera Ribeiro. Rio de Janeiro: Contraponto.

Thiollent, M. (2011) Metodologia da pesquisa-ação. 18 ed. São Paulo: Cortez. 